\title{
Writing the Medical Leave Certificate: What are the Precautions?
}

\author{
Rudrajit Paul
}

\begin{abstract}
Sick leave is a very important part of employment benefit. Doctors are often required to issue such certificates. This article will discuss the rules and ethics of the medical certificate.

Keywords: Confidentiality, Fraud, Leave, Medical certificate, Record. Bengal Physician Journal (2019): 10.5005/jp-journals-10070-6119
\end{abstract}

Doctor, I am ill. Please issue me a medical certificate for my office so that I can take leave.

How many times have you heard this from your patients? If you are a practicing physician, I presume that this is a daily occurrence for you.

But if you remember your college days, there was hardly any lecture or book chapter on this important issue. For example, we have all read about malaria or systemic lupus erythematosus (SLE). But nowhere in those books was written how many days of medical leave are permissible for these diseases. But in professional life, this is one issue every doctor has to deal with. It is just not enough to diagnose a disease and treat it successfully. The physician must also cater to the work absenteeism aspect of the disease.

Now, here comes the question of a delicate balancing act. If someone is ill, then according to international labor laws, he or she is entitled to medical leave. Social security has been defined as a basic human right and paid sick leave is one of the tenets of social security. ${ }^{1}$ A doctor should write the certificate for this purpose. But again, sometimes we see people who just want a leave under the pretext of medical reasons. And it is not always easy to have one right or wrong answer in such cases.

The attempt by some unscrupulous persons to bend the law to their benefit is nothing new. But usually, the police and the judiciary are equipped to deal with such transgressions. Only in case of medical certificate (for sick leave and other purposes), the doctor becomes the responsible person. However, it would not be egregious to say that most physicians in India have only a superficial knowledge of this topic, and they mostly tend to follow their peers or their own judgment. Since sick leave certificate is a legal document with its attendant financial and administrative implications, there is a possibility of this certificate ending up in a court of law and then the doctor may have to justify his or her statement according to not only medical but also legal standards. Hence, doctors issuing such certificates must have a basic understanding of the laws.

In September 2017, five doctors in Delhi lost their registration for issuing "fake" medical leave certificates. ${ }^{2}$ One doctor had issued a 6-month medical certificate for a person. The diagnosis given was disk prolapse L4-L5! And no supporting diagnostic test was available. In another case, a medical leave certificate was issued for 62 days for a case of urinary tract infection (UTI). Another doctor had issued medical certificate for a period of 11 months continuously. ${ }^{2}$ All of these were found to be unethical and illegal by the medical council.

Department of Critical Care Medicine, Institute of Postgraduate Medical Education and Research and Seth Sukhlal Karnani Memorial Hospital, Kolkata, West Bengal, India

Corresponding Author: Rudrajit Paul, Department of Critical Care Medicine, Institute of Postgraduate Medical Education and Research and Seth Sukhlal Karnani Memorial Hospital, Kolkata, West Bengal, India, Phone: +91 9433824341, e-mail: r.paul.medicalcollege@gmail. com

How to cite this article: Paul R. Writing the Medical Leave Certificate: What are the Precautions? Bengal Physician Journal 2019;6(3):67-71.

Source of support: Nil

Conflict of interest: None

The patient who demands a false medical certificate is also not without the chance of jeopardy. Production of false medical leave certificate can also be a ground for termination of service for the employee. ${ }^{3}$ Thus, false medical certificate is an anathema for both the issuing person and the beneficiary.

So, naturally the question arises, how to write a proper certificate for medical leave?

After the aforementioned incident in Delhi, the Delhi Medical Council (DMC) issued a guideline for this purpose. According to this, the following rules should be followed: ${ }^{4}$

- The medical certificate is a legal document. Any false certificates may expose a physician to punitive actions by the medical council and also the civil or criminal courts of law

- Just writing that "this certificate is not for legal purposes" is not a valid statement and does not absolve a physician from the crime of a false certificate

- The certificate should be legible

- The certificates should be based only on facts seen by the doctor. If some of the facts of the illness are based on the patient's history only, that part should be clearly stated. It can be written as "reported by the patient and deemed to be true by the doctor."

- The certificate should have a clear date

- The certificate should have registration number of the physician (even if written in a government hospital) 
Contd...

- The certificate should be prospective. That is, a doctor should state the probable period of absence from the date of issuance of the certificate. A certificate should not be retrospective normally. Sometimes, a short retrospective certificate may be issued, but in that case, the retrospective nature of the certificate must be stated clearly

- The certificate should avoid abbreviations

- The certificate should be addressed to the intended person (employer/school principal) (In other words, generic certificates with the heading "To whom it may concern" should probably be avoided)

- A doctor may write statements like "suitable for light work" or "unfit for certain duties" if it is within the professional expertise of that doctor. For example, a gynecologist may not write whether a patient with leg fracture is suitable for work. Similarly, a physician cannot write whether bed rest is needed after radiotherapy. In the aforementioned Delhi case, the doctor writing the spinal disk prolapse certificate was a pediatrician!! (But he is not qualified to certify whether an adult with disc prolapse needs bed rest. For that an orthopedics specialist or neurosurgeon would be ideal)

- The DMC also states that normally, a certificate should be issued only for a maximum of 15 days. If further leave is needed, further certificates should be issued after that period of time. If a doctor thinks that a long period of absence is desirable, then it is better to refer the case to a medical board of the employer

- The certificate should preferably contain an ID mark of the patient

- And finally, the certificate must be accompanied by a signature or thumb impression of the patient. If it is a minor (in case of schoolchildren), the signature should be that of a guardian. It must be remembered that a doctor in India is not verifying authority. He/she has no way of knowing whether the name given by the patient for certificate purpose is correct. A doctor never asks for ID proof in India, especially in private chambers (in contrast, in the USA, when someone goes for a doctor consultation, social security number has to be provided). Thus, a person may register under a false name and get a certificate for sick leave. While it is true that a doctor-patient relationship depends on trust, still doctors need to take precautions against imposters. So, one insurance for doctors against such crime is the signature

The same rules will apply for government hospital certificates. A government doctor is also subject to harsh punishment if rules are violated.

Ideally, the physician should keep a record of the certificates issued by him or her so that if the patient or a family member tampers with the certificate in any way, it can be verified later in a court of law. This is easy in hospitals. But in private clinics in rural areas, where electricity is not available, let alone a computer, keeping records is very difficult. The author suggests that in those cases, the doctor can at least keep a photo of the certificate. Also, a certificate should be preferably printed with no overwriting or alterations. Generally, duplicate certificates should not be issued and if it is done at all, a written application from the patient should be taken. Also, the word "duplicate" should be clearly mentioned in the certificate.
Also, the number of days that medical leave is recommended should be written in words and not figures. If number of days are written in figures, they can be easily tampered with by adding a " 0 " after or a "1" before the figure. Thus, 7 can be changed to 17 easily. Such minor changes are very difficult to identify later, even with an expert graphologist.

And finally, it must be remembered that a sickness certificate does not end the duty of a doctor. After the patient recovers, the physician must also issue a "fit to work" certificate. This certificate must state the date from which the patient is fit to work and also whether any specific requirements are needed. Sometimes, this is written along with the sick certificate only. Some persons may decide to join duties before the end of the stipulated period of rest. If their employer allows this, then the doctor has no need to issue fit certificate. In the National Health Service (NHS), UK, the form 3 (statement of fitness for work) states that the doctor may indicate whether the patient is fit for work and whether any of the following are needed: ${ }^{5}$

- Phased return to work

- Altered hours

- Amended duties

- Workplace adaptations

Also, a doctor may mention whether any special ongoing treatment will be required, like "Patient needs physiotherapy thrice a week."

Doctor, please write a certificate that I am unable to do heavy work for three months.

This is another request often faced by physicians in India. Especially, this is a common request made by other healthcare staff, and because of the close professional relationship, the doctor may be in a tight spot. A doctor who refuses such certificates may face future hostilities from the colleagues.

Now, here in India, a patient may request the doctor, "Doctor, please write a certificate that I am unable to do night duties because of my illness." While it may be true that a patient may have restrictions in such cases, a doctor should not write "night duties" or such explicit instructions. Based on the above guideline, the doctor may just write "altered duty hours." Now, the issue of night duty must be taken up between the employee, the union, and the employer. It is not the doctors' responsibility to take everything in their own hand and specify exactly what work a patient may or may not do. Sometimes, the presumed restriction to duties may be stated indirectly. For example, for a patient with back pain, a doctor may write

“... suffering from back pain which will make bending forward impossible." Now it is up to the employer to interpret this report and decide accordingly

Another question which arises is, should one write "bedrest" in the certificates? There is no legal need to write that term. The certificate can just be written as "absent from work due to ... illness"

It is not necessary to issue fit certificate just before the person joins service after medical leave. Usually, the employer will allow a stipulated time (e.g., 15 days) within which the certificate has to be produced. Usually, the certificate needs to be signed by the doctor. But some employers may allow only soft copies of certificates. In such cases, the doctor may send the fit certificate by mail to the employer.

It is best not write any detailed psychiatric diagnosis in such medical certificates. Revelation of such a diagnosis may make the 
patient suffer discrimination and derision. It is up to the employee to decide if he/she wants to reveal the psychiatric diagnosis at the workplace.

Also, it must be remembered that any employer is not legally bound to follow recommendations of a medical certificate. They may choose to ignore it, contest it, or seek a second opinion. The doctor should write only the facts based on medical guidelines. (Nowhere in any guideline is it written that a patient of, say, lung malignancy cannot work night hours or "heavy work" is to be avoided for 1 month after dengue fever. Based on clinical judgment, the doctor may feel that some rest is needed. But since this is not written anywhere, it is difficult to defend in court. Thus, a doctor should not also make such detailed statements and just write "amended duties.") He/she must not write something in the certificate which cannot be defended later in front of a shrewd lawyer. For example, if a judge asks a doctor in court, "Doctor, why did you write that this patient of diabetes cannot do night duty? Can you show me some evidence?" Will the doctor be able to answer the judge with supportive evidence?

If a doctor thinks that he/she needs to reassess a patient for fitness at a later date, then the fit certificate can be given conditionally. For example, it may be written that "... Mr. XYZ is fit for work for next 15 days after which he needs to be reassessed to judge his continuing fitness." If the doctor is unfamiliar with any particular profession and does not know what that duty entails, it is always prudent to refer the case to a medical board. This is particularly true for policemen and soldiers. If a policeman asks a doctor to write a medical leave certificate, the doctor should first know what duty that policeman or woman does.

If a patient is admitted to a hospital, the sick certificate, if applicable, may be written at the time of discharge. Or the discharge certificate may clearly mention the date from which the patient is medically permitted to join duties. Alternatively, if the physician is unsure, the case may be referred back to the general practitioner (GP) for future follow-up and fit certificate.

Some employers accept self-certification from their employees for illness of short duration (1-3 days). In the UK, most employers accept up to 6 days of self-declaration. In such cases, a doctor need not write any certificate. Usually, it is absence of longer duration for medical reasons that requires a certificate. In India, the rules are vague. Most employers equate "medical leave" with production of a certificate. But there are many illnesses where the patient need not visit a doctor but only needs to take a few days off for recuperation.

\section{A Special Situation}

In the light of recent coronavirus infection, an employee may be granted sick leave if he is thought to be in the incubation period of the disease and may pose a health hazard to the coworkers. A doctor may certify a person as such and recommend sick leave. For this, the epidemic-specific guidelines should be followed.

Here, the author would also like to include some relevant points from the Australian Medical Council: ${ }^{6}$

- A doctor should write the medical certificate only from the date he/she has seen the patient. If the patient had been taking leave earlier that must be settled between the employer and employee. The physician is responsible only from the time he/ she has encountered the patient. However, the physician may include a note that he thinks the previous period of absence may be reasonable, based on the current condition of the patient. But the employer may not accept that (that is why in the websites of some NHS GP practices, it is written that the patient needs to come at the beginning of the illness for a proper certificate)

- The patient may request the doctor not to write the actual diagnosis in the certificate. This wish for confidentiality must be respected. A doctor is not obliged to reveal the nature of the illness of the employee to the employer. In fact, if it is revealed against the patient's wishes, it may be ground for a legal dispute. Also, no employer has the right to demand medical diagnosis of his employee. (The US Equal Employment Opportunity Commission states that once a doctor certifies that a person is absent for medical reasons, the employer has no right to demand any more information. There is no reason why the same principle cannot apply to India.) But if the patient makes such a request to hide the diagnosis, the doctor must state him/her that the medical certificate may contain insufficient information in that case, and thus, the employer has the right to reject sick leave. This must be negotiated between the employer and employee.

In such cases, a certificate can be issued like

"... I have examined this patient on ... (date) and based on clinical findings and available reports, the patient may require leave for 8 days."

- A doctor has the right to refuse if he thinks the illness does not merit a leave. If the patient had taken a leave, it is his own decision. The patient can then appeal to the employer for a different physician or a medical board

- A medical person cannot issue a self-certificate

- In case of doubt, a doctor should consult their personal lawyer before signing a certificate

Each country has its own set of laws for issuing medical certificates, like acceptable duration, requirement for specialist opinion, etc. The doctor should familiarize himself with the laws of the land. Also, different organizations demand different formats for sick certificate.

\section{Some Gray Areas}

The rules for writing a medical certificate are not just white and black. There are some gray zones where dilemma remains. Let us discuss one or two

- Suppose a patient had consulted a different doctor earlier with all valid documents and reports. Now, she comes to you with all records and asks for a certificate. Can you issue such a certificate? - There is no mention of such a case in any Indian text. So, it is very difficult to give an Indian example. But in other countries like South Africa, ${ }^{7}$ the doctor is allowed to issue a certificate based on past records if he thinks the previous records are acceptable. But in that case, the use of previous records should be mentioned.

- Suppose a patient has consulted you over phone or WhatsApp. Can you issue a certificate based on that?

- Again, this is a controversial area. In the NHS, UK, a GP may issue a certificate based on phone consultation. In New Zealand too, a doctor may decide to certify a patient based on a video consultation. (However, a phone consultation for the purpose of medical certificate is not considered free. For example, in New Zealand, average charge for video consultation is $\$ 50$, or INR 2,200; in the UK, average charge for a 10-minute phone consultation is GBP 40 or 
approximately INR 4,000.) But WhatsApp or such message services or e-mail cannot be the basis for a certificate because you do not see or hear the person. You do not know who is messaging you.

- The patient was earlier seen by a paramedical staff like technician or physiotherapist and found to be ill. Can you give a sick certificate based on that?

- In the UK, a GP is allowed to consider sick notes by nurses or physiotherapists. ${ }^{8}$ But in that case, the note must be written and recorded.

- A patient says "doctor I will be having a colonoscopy today. I cannot go to work. Please issue me a sick certificate"

- Sick certificate is not applicable for diagnostic test days. The leave for that purpose must be settled between employer and employee.

- A patient has two jobs. Should I issue two sick certificates?

- No. there can be only one certificate per consultation.

- The patient had come to you earlier. Now he calls you and requests to send the sick certificate via WhatsApp. Can you do it?

- No, because you cannot have signature of the patient in that certificate. The soft copy of the certificate may be modified to include someone else's name.

- A patient had consulted you earlier. Now she calls you up and says that she is sending someone to your chamber for the fit certificate. Can you do this?

- Ideally, this should not be done. This is risky. You should ideally see the patient at the materialistic moment of issuance of the certificate with your signature. If it is later found that the patient was out of country (via Facebook or Instagram posts) or engaged in some questionable activity at that moment, you may be in a soup.

The final question, something which is not a legal matter, but a social issue is whether a doctor should charge a fee for issuing such certificates?

It is very difficult to give a single answer to this question. So, the author will refer to the website of a UK private practice for relevant points: ${ }^{9}$

The primary duty of a GP is to provide services for ill patients. Filling forms and writing certificates are an extra burden which is outside primary duty of a doctor. Hence, they incur a fee. Also, a doctor has to go through the entire medical record of a patient to complete the certificate, and any faults there may cause problems with the medical council or even the police. This level of meticulous work incurs a fee.

The British Medical Association also supports this fee for issuing certificates. ${ }^{10}$ Their suggested fees range from GBP 16 for a "statement of fact" (around Rs 1,500) to GBP 125 (around Rs 11,000) for a detailed certificate. A physician is responsible for every word of the certificate and may have to face legal battles for it (which may make him destitute). There is no reason why it should be done without a reasonable fee.

\section{Suggestions}

- The Indian Medical Council should make a standard form for sick certificates. Such forms should be available online for download

- Medical boards should be set up by all employers for this purpose

- There should be a guideline by Association of Physicians of India (API) for the duration of leave permissible in some common diseases like dengue fever or meningitis. This will save doctors from undue pressure by the patients' relatives to issue certificates for long duration of leave

- Also, clear guidelines need to be established for phone or WhatsApp consultations.

- Also, the guidelines for amended duties should be published by professional bodies. For example, can a patient on insulin work night shifts? Can a patient of epilepsy work in traffic guard? How will a doctor issue certificates in those cases?

Finally, in 2012, the Mumbai High Court observed that a medical certificate is not always sufficient proof of fitness. ${ }^{11}$ The court may decide to overturn it or call the medical expert in witness box for further clarification. And finally, we should all remember the famous Abdul Karim Telgi case. ${ }^{12}$ Telgi allegedly obtained questionable medical certificates which enabled him to get bail on health grounds. Both the doctors who signed that medical certificate were sentenced to 7 years of rigorous imprisonment. Both were government doctors.

In the current days of social media, sick certificates may come under intense scrutiny if a person, who is on sick leave, is found to be enjoying himself/herself via Facebook posts. This may frustrate the employer, who may then complain against the doctor. Actual cases of people getting fired for posting vacation pictures during their sick leave have been recorded.

After everything is said and done, a doctor may be requested by a close family member or friend for a medical certificate. The Australian Medical Council explicitly advises doctors not to treat close relations. The ethical guidelines for American Medical Association also states that (opinion 8.19) doctors should not generally treat themselves or members of their immediate family. But no such rule is followed in India. Can a doctor always refuse such a certificate, even if he/she has reservations?

A valid point: Dentists are also allowed to issue sick certificates for dental procedures.

\section{Controversial Point}

Do doctors need to certify for menstrual leave? The concept of monthly menstrual leave is in vogue in many Asian countries like Japan, Indonesia, and South Korea. It is supposed to be a paid leave. But that will be on self-declaration only. Doctors need to certify only if additional leave days are required for conditions like menorrhagia.

\section{Take-home Messages}

The take-home messages from this discussion are:

- A doctor should never issue a certificate which cannot be defended later

- It is not mandatory to write the diagnosis in a sick certificate if the patient requests confidentiality

- The duration of absence must be based on clinical judgment. If needed, repeat visits for issuing fresh certificates may be planned

- A doctor may not issue self-certificate

- The decision to allow sickness benefits will be taken by the employer only. The doctor should only state the medical facts and not go beyond that duty.

**Although this discussion is meant mainly for sick certificate, the same rules will apply for other similar medical certificates like "fit to fly," "fit for sports," etc. 


\section{References}

1. Scheil-Adlung X, Sandner L. Paid sick leave: incidence, patterns and expenditure in times of crises. ESS paper: 27. International Labour Office, Social Security Department. Geneva: ILO; 2010.

2. Sharma P, Delhi Medical Council suspends doctors for issuing fake medical leave certs. India Today (Internet). [Published 2017 Sep 20; Cited 2020 Feb 22]. Available online from https://www.indiatoday. in/mail-today/story/delhi-medical-council-suspends-doctors-forissuing-fake-medical-leave-certificates-1048361-2017-09-20.

3. Agencies. Employee can be sacked for unauthorised sick leave: SC. Economic Times [2008 Feb 24]. [Cited 2020 Feb 22]. Available online from https://economictimes.indiatimes.com/jobs/employee-canbe-sacked-for-unauthorised-sick-leave-sc/articleshow/2809286. $\mathrm{cms}$ ?from $=\mathrm{mdr}$.

4. DMC guidelines for issuing a medical certificate. [Cited $2020 \mathrm{Feb} 22]$. Available online from http://www.delhimedicalcouncil.org/images/ New\%20Doc\%202019-11-29\%2017.33.21.pdf.

5. Fit Notes: A guide for hospital doctors. University Hospitals, Plymouth. [Cited 2020 Feb 22]. Available online from https://www.england.nhs. uk/south/wp-content/uploads/sites/6/2019/03/fit-notes-briefing-aguide-for-Hospital-Doctors.-V1.-FEB2019.pdf.

6. Medical certificates: what you should know. Medical Council of New South Wales. [Cited 2020 Feb 24]. Available online from https://www. mcnsw.org.au/medical-certificates-what-you-should-know.
7. Verwey $\mathrm{H}$, Medical certificates: avoiding the pitfalls. Medical Protection. [Posted 2015 May 19; Cited 2020 Feb 23]. Available online from https://www.medicalprotection.org/southafrica/casebookmay-2015/medical-certificates-avoiding-the-pitfalls.

8. Getting the most out of the fit note: GP Guidance. Department for Work and Pensions. [Published 2013 March; Cited 2020 Feb 23]. Available online from https://assets.publishing.service.gov. uk/government/uploads/system/uploads/attachment_data/ file/271466/fitnote-gps-guidance-jan-14.pdf.

9. Private Medical reports and fees. Beckett house practice. [Cited 2020 Feb 23]. Available online from https://www.becketthousepractice. nhs.uk/medical-reports-and-fees.

10. Kleinman Z, Why NHS doctors charge patients for letters. BBC. [Posted 2013 Aug 17; Cited 2020 Feb 23]. Available online from https://www. bbc.com/news/business-your-money-23693468.

11. Ganjapure V, Medical certificate not a complete proof of fitness: HC. The Times of India, Dec 27, 2012. [Cited 2020 Feb 23]. Available online from https://timesofindia.indiatimes.com/city/ nagpur/Medical-certificate-not-a-complete-proof-of-fitness-HC/ articleshow/17774953.cms.

12. PTI, Telgi, 2 doctors sentenced to 7 years in jail. Hindustan Times, June 22, 2007. [Cited 2020 Feb 23]. Available online from https://www. hindustantimes.com/india/telgi-2-doctors-sentenced-to-7-years-injail/story-QHbhmqlHxGpjBPiu1aRj0O.html. 